\title{
KARYOTYPE IN PAEONIA INTERMEDIA C.A. MEY
}

\author{
SHI-QUAN WANG ${ }^{1}$ \\ Ministry of Education Key Laboratory for Tropical Animal and Plant Ecology, \\ College of Life Sciences, Hainan Normal University, Haikou 571158, China
}

Key words: Karyotype, Paeonia intermedia C. A. Mey.

\begin{abstract}
The chromosome number and karyotype of three populations in Paeonia intermedia C.A. Mey are presented in this paper. The populations, sampled from Altai Prefecture in Xinjiang, China, are diploids $(2 \mathrm{n}=$ 10 ), with 2A type karyotype and the karyotypic formula of $2 n=2 x=10=6 m+2 s m+2$ st. There was no obvious differentiation among all the three sections of the genus Paeonia based on parameters of arm ratio and ratio of the longest/shortest chromosome $\left(\mathrm{L}_{1} / \mathrm{L}_{n}\right)$. There is merely slight difference between the woody section (Sect. Moutan) and the herbaceous sections (Sects. Onaepia and Paeonia).
\end{abstract}

The genus Paeonia L. (Paeoniaceae) comprised of approximately 32 species of shrubs and perennial and are widely distributed in the Northern Hemisphere (Hong et al. 2001). The genus is divided into three sections (Sect.) namely, Moutan DC., Onaeopia Lindley and Paeonia L. (Stern 1946). Sect. Paeonia L., with their chromosomes large in size and low in number, has attracted considerable cytological and cytogenetical studies since 1930's. Among the species, so far cytologically studied from Sect. Paeonia are either diploid or tetraploid $(2 \mathrm{n}=20)$, only two species in this section were found intraspecifically both diploid and tetraploid (Dark 1936, Stern 1946, Hong et al. 1988), i.e., Paeonia obovata and P. mairei. However, because of the absence of a universal parameter to measure karyotype, only a few species reported have been sufficiently analysed karyotypically so far. The comparisons among the well analysed species were mostly made between diploids and tetraploids, or between two sections (Tzanoudakis 1983, Punina 1987, Hong et al. 1988, Zhang and Hou 1996).

In this species, the accessions from North Xinjiang were once misplaced under the name of $P$. anomala and $P$. anomala var. intermedia (Stern 1946). According to the previous study, $P$. intermedia was well isolated with and did not hybridize with a sympatric diploid species, $P$. anomala (Hong et al. 1994). However, the ploidy level and karyotype of Xinjiang's population in $P$. intermedia was not known previously. Therefore, the present research was undertaken to count the chromosomal number and to analyze the karyotype of the Aletai populations in $P$. intermedia.

Paeonia intermedia C.A. Mey., an endangered species with very few individuals in each population, was collected from Altai Prefecture, Xinjiang, China. Fifteen individuals of three populations with right cell division stages were successfully fixed through a wide survey that found totally over 150 individuals. The collection and fixation were performed for each individual separately. The plants of population-1 (individuals numbered from 131 - 150) grew at sunny hillside at an altitude of $1650 \mathrm{~m}$, along with sparse grasses, in Hemu; population-2 and population -3 (numbered from 164 - 173 and from 175 - 186, respectively) grew at sunny hillside of an altitude of $1400 \mathrm{~m}$, along with shrubs and grasses in Jiadengyu. The three populations are isolated from each other by mountains, rivers and roads. The voucher specimens from all populations are deposited in the herbarium (PE), Institute of Botany, the Chinese Academy of Sciences.

Author for correspondence: <wsqmah@163.com>. ${ }^{1}$ College of Life Science, Hainan Normal University, Haikou 571158, China. 
Flower buds used for chromosome study were fixed in Carnoy's solution ( 3 absolute ethanol : 1 glacial acetic acid). After fixation for at least 24 hrs, the buds were transferred into $70 \%$ ethanol and stored at $-20^{\circ} \mathrm{C}$ until further use.

The chromosome slides were made by conventional squashing method and stained with modified carbol-fuchsin (Darlington and La Cour 1975), and were mounted with Canada balsam. The photomicrographs were taken using a Leitz Orthoplan microscope under 100×. At least five cells were calculated and the results were shown in Table 1 . The classification of karyotypes was followed after Stebbins (1971). The ratio of the longest/shortest chromosome $\left(\mathrm{L}_{1} / \mathrm{L}_{\mathrm{n}}\right)$ was calculated according to Zhang (1998).

The materials used for karyotypic analyses were individuals numbered from 131 - 186. The 15 individuals of three populations are all diploids, $2 n=10$ (Fig. 1). The karyotype formula are shown in Table 1 . The karyotype of $P$. intermedia was similar to all of the reported species in this genus, and all are 2A type. The chromosomes can be classified into three types. Type I: including chromosome 1, 2 and 3, was metacentric chromosome; Type II: only including cromosome 4, was submetacentric; Type III: only including cromosome 5, was subtelocentric (Fig. 1).

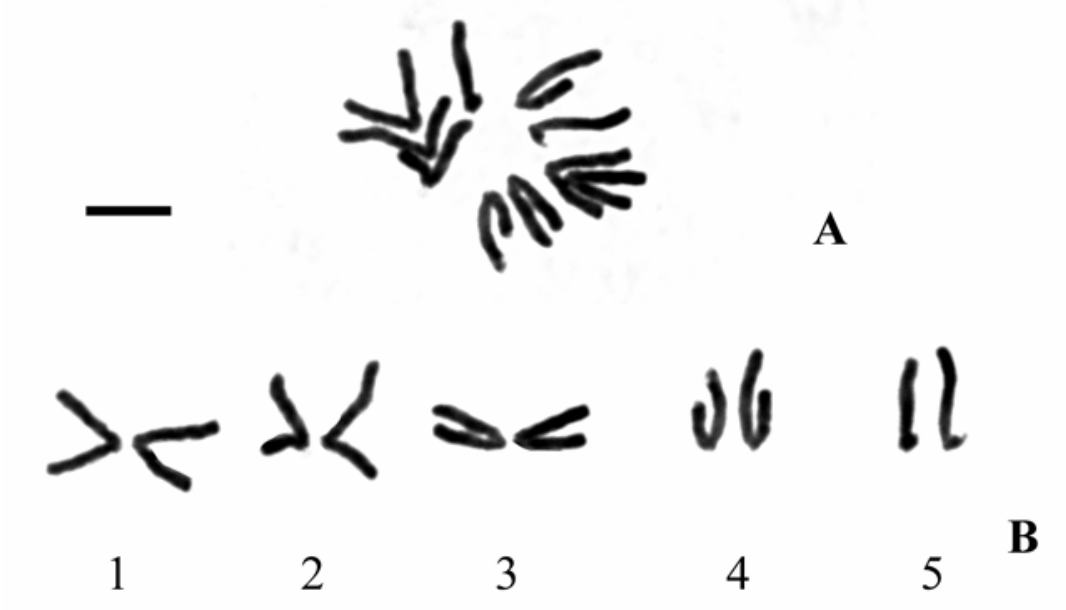

Fig. 1. Chromosomes of diploid Paeonia intermedia (A) well spread metaphase $(2 \mathrm{n}=2 \mathrm{x}=10)$.

(B) Karyotype, chromosomes 1 - 5. (Bar $=10 \mu \mathrm{m})$.

The arm ratio of chromosome 1 in P. intermedia ranged from 1.12 to 1.30 (Table 1), which is consistent with that of the other species in Sect. Paeonia reported by Hong (1988). Furthermore, the arm ratio of chromosome 1 in Sect. Paeonia is similar (1.12 - 1.37), and does not overlap with that of chromosome 1 in Sect. Moutan (1.43 - 1.60) (Hong et al. 1988). At the same time, the armratio of chromosome 1 in Sect. Onaeopia (1.13 - 1.2) (Stebbins and Ellerton 1939) is not overlap with that in Sect. Moutan, either. This result further confirms that the woody section (Sect. Moutan) apparently differentiated from the herbaceous one (Sects. Paeonia and Onaeopia).

The differentiation of karyotype in this genus also exists on the ratio of the longest chromosome/shortest one. The ratio of the longest/shortest chromosome $\left(\mathrm{L}_{1} / \mathrm{L}_{\mathrm{n}}\right)$ were calculated and the value ranged from $1.38-1.53$ in P. intermedia, while the $\mathrm{L}_{1} / \mathrm{L}_{\mathrm{n}}$ value in $P$. californica is 1.30 and 1.80 in P. brownii in Sect. Onaeopia (Stebbins and Ellerton 1939), and 1.40 in Sect. Moutan (Hong et al. 1988). 
Table 1. The parameters of chromosomes in Paeonia intermedia

\begin{tabular}{|c|c|c|c|c|c|c|c|}
\hline Population & Individual & $\begin{array}{l}\text { Chromosome } \\
\text { number }\end{array}$ & $\begin{array}{l}\text { Absolute } \\
\text { length }(\mu \mathrm{m})\end{array}$ & $\begin{array}{l}\text { Relative } \\
\text { length }\end{array}$ & Arm ratio & $\begin{array}{l}\text { Chr. } \\
\text { Type* }\end{array}$ & $\mathrm{L}_{\mathrm{l}} / \mathrm{L}_{\mathrm{n}}$ \\
\hline \multirow[t]{25}{*}{1} & & 1 & $12.07 \pm 1.21$ & $13.15+10.70=23.85$ & $1.25 \pm 0.21$ & $\mathrm{~m}$ & 1.49 \\
\hline & & 2 & $11.01 \pm 1.31$ & $11.95+9.77=21.72$ & $1.24 \pm 0.22$ & $\mathrm{~m}$ & \\
\hline & 131 & 3 & $10.21 \pm 1.13$ & $11.54+8.60=20.14$ & $1.36 \pm 0.21$ & $\mathrm{~m}$ & \\
\hline & & 4 & $9.34 \pm 1.14$ & $12.42+5.99=18.41$ & $2.20 \pm 0.24$ & $\mathrm{sm}$ & \\
\hline & & 5 & $8.12 \pm 1.15$ & $12.57+3.43=16.00$ & $3.70 \pm 0.39$ & st & \\
\hline & 134 & 1 & $13.41 \pm 1.42$ & $12.77+11.01=23.78$ & $1.16 \pm 0.08$ & $\mathrm{~m}$ & 1.48 \\
\hline & & 2 & $12.25 \pm 1.10$ & $11.59+10.15=21.74$ & $1.15 \pm 0.10$ & $\mathrm{~m}$ & \\
\hline & & 3 & $11.32 \pm 1.21$ & $10.8+9.25=20.05$ & $1.18 \pm 0.16$ & $\mathrm{~m}$ & \\
\hline & & 4 & $10.3 \pm 0.94$ & $12.09+6.19=18.28$ & $1.97 \pm 0.20$ & sm & \\
\hline & & 5 & $9.06 \pm 0.54$ & $12.46+3.68=16.14$ & $3.41 \pm 0.32$ & st & \\
\hline & & 1 & $13.15 \pm 0.73$ & $12.68+10.92=23.60$ & $1.17 \pm 0.16$ & $\mathrm{~m}$ & 1.51 \\
\hline & & 2 & $12.35 \pm 1.15$ & $12.19+9.95=22.14$ & $1.23 \pm 0.14$ & $\mathrm{~m}$ & \\
\hline & 135 & 3 & $11.36 \pm 0.66$ & $11.31+9.07=20.38$ & $1.26 \pm 0.16$ & $\mathrm{~m}$ & \\
\hline & & 4 & $10.17 \pm 0.82$ & $11.93+6.33=18.26$ & $1.89 \pm 0.17$ & sm & \\
\hline & & 5 & $8.70 \pm 0.39$ & $12.20+3.43=15.63$ & $3.58 \pm 0.39$ & st & \\
\hline & 148 & 1 & $12.55 \pm 1.31$ & $12.25+10.97=23.22$ & $1.12 \pm 0.08$ & $\mathrm{~m}$ & 1.44 \\
\hline & & 2 & $11.78 \pm 1.01$ & $11.83+10.01=21.84$ & $1.19 \pm 0.13$ & $\mathrm{~m}$ & \\
\hline & & 3 & $10.93 \pm 0.91$ & $11.07+9.18=20.25$ & $1.22 \pm 0.15$ & $\mathrm{~m}$ & \\
\hline & & 4 & $9.99 \pm 0.82$ & $12.56+5.95=18.51$ & $2.15 \pm 0.35$ & sm & \\
\hline & & 5 & $8.70 \pm 0.34$ & $12.65+3.53=16.18$ & $3.68 \pm 0.71$ & st & \\
\hline & 150 & 1 & $11.08 \pm 1.58$ & $13.54+10.88=24.42$ & $1.26 \pm 0.18$ & $\mathrm{~m}$ & 1.53 \\
\hline & & 2 & $9.92 \pm 1.33$ & $11.83+10.04=21.87$ & $1.19 \pm 0.14$ & $\mathrm{~m}$ & \\
\hline & & 3 & $9.07 \pm 1.28$ & $11.25+8.73=19.98$ & $1.30 \pm 0.16$ & $\mathrm{~m}$ & \\
\hline & & 4 & $8.09 \pm 1.30$ & $11.87+5.92=17.79$ & $2.02 \pm 0.22$ & sm & \\
\hline & & 5 & $7.22 \pm 0.91$ & $12.47+3.48=15.95$ & $3.64 \pm 0.55$ & st & \\
\hline \multirow[t]{25}{*}{2} & 164 & 1 & $10.36 \pm 1.02$ & $13.17+10.18=23.34$ & $1.30 \pm 0.09$ & $\mathrm{~m}$ & 1.41 \\
\hline & & 2 & $9.53 \pm 0.84$ & $12.12+9.38=21.50$ & $1.31 \pm 0.15$ & $\mathrm{~m}$ & \\
\hline & & 3 & $8.93 \pm 0.83$ & $10.66+9.48=20.14$ & $1.13 \pm 0.11$ & $\mathrm{~m}$ & \\
\hline & & 4 & $8.25 \pm 0.90$ & $12.80+5.76=18.56$ & $2.26 \pm 0.37$ & sm & \\
\hline & & 5 & $7.33 \pm 0.97$ & $13.02+3.44=16.46$ & $3.82 \pm 0.50$ & st & \\
\hline & 165 & 1 & $10.59 \pm 0.80$ & $12.87+11.07=23.94$ & $1.17 \pm 0.13$ & $\mathrm{~m}$ & 1.48 \\
\hline & & 2 & $9.68 \pm 0.71$ & $11.97+9.94=21.91$ & $1.22 \pm 0.17$ & $\mathrm{~m}$ & \\
\hline & & 3 & 8.860 .63 & $11.30+8.74=20.04$ & $1.31 \pm 0.18$ & $\mathrm{~m}$ & \\
\hline & & 4 & $7.92 \pm 0.48$ & $11.98+5.97=17.95$ & $2.03 \pm 0.30$ & sm & \\
\hline & & 5 & $7.14 \pm 0.47$ & $12.59+3.59=16.18$ & $3.52 \pm 0.32$ & st & \\
\hline & 167 & 1 & $11.17 \pm 0.76$ & $12.65+10.88=23.53$ & $1.17 \pm 0.11$ & $\mathrm{~m}$ & 1.45 \\
\hline & & 2 & $10.41 \pm 0.62$ & $12.17+9.76=21.93$ & $1.26 \pm 0.19$ & $\mathrm{~m}$ & \\
\hline & & 3 & $9.71 \pm 0.75$ & $11.42+9.06=20.48$ & $1.28 \pm 0.20$ & $\mathrm{~m}$ & \\
\hline & & 4 & $8.82 \pm 0.58$ & $12.32+6.26=18.58$ & $2.00 \pm 0.27$ & sm & \\
\hline & & 5 & $7.69 \pm 0.48$ & $12.55+3.65=16.20$ & $3.48 \pm 0.47$ & st & \\
\hline & 170 & 1 & $12.00 \pm 1.29$ & $12.92+11.14=24.06$ & $1.16 \pm 0.12$ & $\mathrm{~m}$ & 1.44 \\
\hline & & 2 & $10.52 \pm 0.79$ & $11.79+9.35=21.14$ & $1.28 \pm 0.21$ & $\mathrm{~m}$ & \\
\hline & & 3 & $10.05 \pm 0.79$ & $11.53+8.66=20.19$ & $1.34 \pm 0.16$ & $\mathrm{~m}$ & \\
\hline & & 4 & $9.12 \pm 0.89$ & $12.36+5.95=18.31$ & $2.08 \pm 0.18$ & sm & \\
\hline & & 5 & $8.34 \pm 0.68$ & $13.15+3.61=16.76$ & $3.67 \pm 0.39$ & st & \\
\hline & 173 & 1 & $11.54 \pm 1.43$ & $13.30+10.95=24.25$ & $1.23 \pm 0.17$ & $\mathrm{~m}$ & 1.51 \\
\hline & & 2 & $10.22 \pm 0.90$ & $11.76+9.79=21.55$ & $1.22 \pm 0.22$ & $\mathrm{~m}$ & \\
\hline & & 3 & $9.43 \pm 0.79$ & $10.62+9.27=19.89$ & $1.15 \pm 0.11$ & $\mathrm{~m}$ & \\
\hline & & 4 & $8.66 \pm 0.95$ & $12.09+6.15=18.24$ & $2.03 \pm 0.47$ & sm & \\
\hline & & 5 & $7.62 \pm 0.70$ & $12.49+3.59=16.08$ & $3.51 \pm 0.43$ & st & \\
\hline
\end{tabular}


(Contd.)

\begin{tabular}{|c|c|c|c|c|c|c|c|}
\hline \multirow[t]{25}{*}{3} & \multirow[t]{5}{*}{175} & 1 & $11.75 \pm 0.70$ & $13.04+10.81=23.85$ & $1.18 \pm 0.14$ & $\mathrm{~m}$ & \multirow[t]{5}{*}{1.42} \\
\hline & & 2 & $10.86 \pm 0.49$ & $12.03+10.05=22.08$ & $1.18 \pm 0.18$ & $\mathrm{~m}$ & \\
\hline & & 3 & $10.10 \pm 0.87$ & $11.23+8.92=20.15$ & $1.28 \pm 0.22$ & $\mathrm{~m}$ & \\
\hline & & 4 & $9.09 \pm 0.84$ & $12.25+6.24=18.49$ & $1.92 \pm 0.17$ & sm & \\
\hline & & 5 & $8.27 \pm 0.55$ & $13.32+3.57=16.89$ & $3.73 \pm 0.73$ & st & \\
\hline & \multirow[t]{5}{*}{177} & 1 & $12.87 \pm 0.43$ & $12.50+10.69=23.19$ & $1.18 \pm 0.15$ & $\mathrm{~m}$ & \multirow[t]{5}{*}{1.44} \\
\hline & & 2 & $12.05 \pm 0.37$ & $11.38+10.34=21.71$ & $1.10 \pm 0.06$ & $\mathrm{~m}$ & \\
\hline & & 3 & $11.57 \pm 0.31$ & $11.41+9.44=20.85$ & $1.22 \pm 0.13$ & $\mathrm{~m}$ & \\
\hline & & 4 & $10.06 \pm 1.00$ & $12.37+5.73=18.10$ & $2.20 \pm 0.38$ & sm & \\
\hline & & 5 & $8.96 \pm 0.37$ & $12.53+3.61=16.14$ & $3.50 \pm 0.38$ & st & \\
\hline & \multirow[t]{5}{*}{180} & 1 & $13.30 \pm 1.14$ & $13.03+11.11=24.14$ & $1.18 \pm 0.11$ & $\mathrm{~m}$ & \multirow[t]{5}{*}{1.52} \\
\hline & & 2 & $12.14 \pm 1.06$ & $12.18+9.86=22.04$ & $1.25 \pm 0.17$ & $\mathrm{~m}$ & \\
\hline & & 3 & $11.00 \pm 0.91$ & $11.11+8.87=19.98$ & $1.26 \pm 0.14$ & $\mathrm{~m}$ & \\
\hline & & 4 & $9.88 \pm 0.66$ & $11.89+6.07=17.96$ & $1.98 \pm 0.28$ & sm & \\
\hline & & 5 & $8.74 \pm 0.58$ & $12.46+3.42=15.88$ & $3.74 \pm 0.75$ & st & \\
\hline & \multirow[t]{5}{*}{183} & 1 & $11.94 \pm 1.37$ & $12.73+10.26=22.99$ & $1.25 \pm 0.16$ & $\mathrm{~m}$ & \multirow[t]{5}{*}{1.38} \\
\hline & & 2 & $10.67 \pm 1.46$ & $11.00+9.51=20.51$ & $1.16 \pm 0.08$ & $\mathrm{~m}$ & \\
\hline & & 3 & $10.18 \pm 1.42$ & $10.87+8.72=19.59$ & $1.25 \pm 0.13$ & $\mathrm{~m}$ & \\
\hline & & 4 & $9.85 \pm 1.12$ & $12.79+6.17=18.96$ & $2.12 \pm 0.39$ & sm & \\
\hline & & 5 & $8.64 \pm 0.51$ & $12.96+3.75=16.71$ & $3.49 \pm 0.36$ & st & \\
\hline & \multirow[t]{5}{*}{186} & 1 & $12.12 \pm 0.57$ & $13.02+11.41=24.43$ & $1.15 \pm 0.10$ & $\mathrm{~m}$ & \multirow[t]{5}{*}{1.49} \\
\hline & & 2 & $10.87 \pm 0.92$ & $12.26+9.60=21.86$ & $1.29 \pm 0.16$ & $\mathrm{~m}$ & \\
\hline & & 3 & $9.88 \pm 0.99$ & $11.33+8.51=19.84$ & $1.35 \pm 0.18$ & $\mathrm{~m}$ & \\
\hline & & 4 & $8.73 \pm 0.92$ & $11.53+6.00=17.53$ & $1.93 \pm 0.23$ & sm & \\
\hline & & 5 & $8.12 \pm 0.62$ & $12.80+3.54=16.34$ & $3.65 \pm 0.36$ & st & \\
\hline
\end{tabular}

${ }^{*}$ Chr. type: Chromosome type, classified according to Stebbins (1971).

$\mathrm{L}_{1}=$ The longest chromosome; $\mathrm{L}_{\mathrm{n}}=$ The shortest chromosome.

This is the first time to report the chromosome number and karyotype in Paeonia intermedia. Due to historical taxonomic confusion of this species, especially with $P$. anomala, this research added valuable information to cytological data in genus Paeonia.

In all the three sections of this genus, karyotypic asymmetry varies slightly. However, from the meiotic studies (Sax 1937, Stebbins and Ellerton 1939, Walters 1942, Zhang et al. 1997, Wang and Zhang 2007, Wang et al. 2008), a great deal of abnormal meiotic configurations were found in all of the individuals observed, indicating that there existed many chromosome structural variations in this genus. These phenomena are contradictory to the karyotypic consistence recognized in Paeonia. In order to understand the contradiction better, further investigation and evidence are needed.

\section{Acknowledgements}

The author thanks Mrs. Jian Wang, Han Mu, Gui-zhong Zhang of the Institute of Forestry Science in Altai for helping in material collection. This research was supported by the National Natural Science Foundation of China (30430030, 30121003), the Natural Science Foundation of Hainan Province (310041), and the Key discipline of Botany of Hainan Normal University (HS-12011-071001). 


\section{References}

Dark SOS 1936. Meiosis in diploid and tetraploid Paeonia species. J. Genet. 32: 353-372.

Darlington CD and LF Lacour 1975. The Handling of Chromosomes, 6th ed. Halsted Press, John Wiley and Sons Inc., New York.

Hong DY, KY Pan and XY Li 1994. Paeonia in Xinjiang, China. Acta Phytotax. Sin. 32: 349-355.

Hong DY, KY Pan and NJ Turland 2001. Paeoniaceae. In: Wu Z Y, Raven P H and Hong DY (eds.): Flora of China. Vol. 6: 127-132. Science Press and Missouri Botanic Garden Press.

Hong DY, ZX Zhang and XY Zhu 1988. Studies on the genus Paeonia (1) - Report of karyotypes of some wild species in China. Acta Phytotax. Sin. 26: 33-43.

Punina EO 1987. Karyological study of species of the genus Paeonia (Paeoniaceae) from the Caucasus. Bot. J. 72: 1504-1514.

Sax K 1937. Chromosome inversion in Paeonia suffruticosa. Cytologia Fujii Jub. Vol.: 108-114.

Stebbins GL 1971. Chromosomal evolution in higher plants. Edward Arnold, London.

Stebbins GL and S Ellerton 1939. Structural hybridity in Paeonia californica and P. Brownii. J. Genet. 38: 1-36.

Stern FC 1946. A study of the genus Paeonia. The Royal Horticultural Society, London.

Tzanoudakis DM 1983. Karyotypes of four wild Paeonia species from Greece. Nord. J. Bot. 3: 307-318.

Walters JL 1942. Distribution of structural hybrids in Paeonia californica. Amer. J. Bot. 29: 270-275.

Wang SQ and D Zhang 2007. Chromosomal inversion heterozygosity in Paeonia intermedia (Paeoniaceae). Plant Sci. 172: 380-392.

Wang SQ, D Zhang and J Pan 2008. Chromosome inversion heterozygosity in Paeonia decomposita (Paeoniaceae). Caryologia 61: 128-134.

Zhang DM 1998. Systematic of the Tribe Ophiopogoneae (Liliaceae s.1.) with special reference to karyotypes and chromosomal evolution. In: Cathaya Vol. 10. Beijing: International Academic Publishers.

Zhang SZ, KY Pan, D Zhang and DY Hong 1997. Observations on abnormal meiosis of pollen mother cells in Paeonia suffruticosa subsp. spontanea. Acta Bot. Sin. 39: 397-404.

Zhang ZP and XG Hou 1996. Karyotype analysis of Paeonia ostii. Hereditas 18: 3-6. 